\title{
The Gold Coast Transformed: From Wilderness to Urban Ecosystem
}

Edited by Tor Hundloe, Bridgette McDougall and Craig Page, Clayton, Vic, CSIRO

Publishing, 2015, 210 pp., \$59.95 (paperback), ISBN 978-1-48630-329-8

\author{
Karine Dupre
}

Environment, Planning and Architecture, Griffith University, Australia

Reflecting a rising tide of interest in Australia's tourist and sixth most populated city, three edited books on the city of Gold Coast were published in 2015-2016: The Gold Coast Transformed: From Wilderness to Urban Ecosystem, edited by Tor Hundloe, Bridgette McDougall and Craig Page; GC30+: Documenting the Gold Coast Architecture Awards, 1984-2013 edited by Andrew Leach, Katherine Rickard and Finn Jones; and Off the Plan: The Urbanisation of the Gold Coast, edited by Caryl Bosman, Aysin Dedekorkut-Howes and Andrew Leach (2016).

Whilst the two last volumes are predominantly concerned with the architecture, urbanisation and development of the Gold Coast, the main perspective of The Gold Coast Transformed: From Wilderness to Urban Ecosystem is to look at the changes of the city from an environmental focus. This book draws on the expertise of 13 contributors from diverse backgrounds (environmental education, sustainable science, design, urban planning, etc.), but who are all currently teaching and/or researching at Bond

University. After an introductory chapter by Tor Hundloe and Craig Page, 16 other chapters are pro- posed to offer a comprehensive assessment of the environmental impact of the construction of the city of Gold Coast. Topics include past and current snapshots of the city (Chapters 4, 3 and 2, 15 respectively), assessment on a diversity of natural systems (forest, beaches, water, wildlife - Chapters 5-9), tourist attractions (themes parks, David Fleay's legacy, and heritage - Chapters 10-12), and reflection on green energy and environmental compliancy and challenges (Chapters 13 and 14). Chapter 16 is an "attempt to bring together the various strands of our enquiries so to assess and report on the Gold Coast's 'state of the environment"' (p. 18), while a surprising concluding chapter provides a list of native plant foods on the GoldCoast.

Despite multiple authors, there is a consistency across the sections through the environmental focus, the level of information and language accessible to the general public. As a result, contributions in this book have maybe a more practical aim and present a plain spectrum of the issues raised by the developments of the Gold Coast. 
However, the prose in The Gold Coast Transformed: From Wilderness to Urban Ecosystem is at times too simple and the chapters are too inconsistent both in style and content. For example, some chapters have few if not any references at all; chapters range from slightly over 3 pages (Chapter 13) to 20 pages (Chapter 1); and the text list format of some sections impoverishes the reading experience (Chapters 14, 15 and 16 for instance). Additionally, the location of colour plates (pp. 67-74) does not make sense since these plates are referenced throughout the full book until page 185. Most importantly, the reader is too often left with the presentation of facts and less with problematised challenges and conceptual categories. This feeling is accentuated by the fact that a large amount of the tables and data are direct extracts from the Gold Coast City Council. More analytical and synthetical illustrations to the text might have added a richer layer to this book. At last, the concluding chapter raises some questions, as it is not clear why a list of native plant foods on the Gold Coast is relevant to conclude the book.

There is no doubt that there is an interest in the focus of The Gold Coast Transformed: From Wilderness to Urban Ecosystem, but the book is not suited well for those seeking to understand how the Gold Coast case study can make a contribution to environmental studies theory. This notwithstanding, it was never the aim of the book's editors but rather to "seek to have our readers, of whatever age, come to understand the when, why and how of the building of the city of Gold Coast" (p. ix). In this aspect, one can confirm it reaches its goal as one general audience book.

\section{References}

1. Bosman, C., Dedekorkut-Howes, A., and Leach, A., eds., 2016. Off the plan: the urbanisation of the gold coast (Clayton, CSIRO).

2. Leach, A., Rickard, K., and Jones, F., eds., 2015. Documenting the Gold Coast Architecture Awards, 1984-2013. Urban Research Progam Research Monograph 15. Gold Coast: Griffith University. 